\title{
Severe hyponatremia due to hypopituitarism with adrenal insufficiency: report on 28 cases
}

\author{
Sven Diederich, Norma-Fiona Franzen, Volker Bähr and Wolfgang Oelkers \\ Division of Endocrinology and Diabetes, Klinikum Benjamin Franklin, Freie Universität Berlin, Hindenburgdamm 3012200 Berlin, Germany \\ (Correspondence should be addressed to W Oelkers; Email: oelkersw@zedat.fu-berlin.de)
}

\begin{abstract}
Objective: Severe hyponatremia due to hypopituitarism and adrenal insufficiency can be lifethreatening, and treatment with glucocorticoids is very effective once the diagnosis of the underlying disorder has been made. In our experience, the diagnosis of hypopituitarism in hyponatremic patients is often overlooked.

Methods: In a retrospective study we screened the files of 185 patients with severe hyponatremia $(<130 \mathrm{mmol} / \mathrm{l})$ that had been seen in one endocrinological unit of a university hospital between 1981 and 2001 in order to describe the clinical spectrum of patients with hyponatremia and hypopituitarism including secondary adrenal insufficiency.

Results: In 139 cases it was possible to clearly ascribe the patients to the pathophysiological groups of (i) primary sodium deficiency, (ii) edematous disorders, and (iii) normovolemic disorders including the 'syndrome of inappropriate secretion of antidiuretic hormone' (SIADH). Twenty-eight patients with severe 'normovolemic hyponatremia' (serum sodium: $116 \pm 7 \mathrm{mmol} / \mathrm{l}$, mean \pm S.D.) had hypopituitarism and secondary adrenal insufficiency as shown by basal cortisol measurements and dynamic tests of adrenal function. In 25 cases of this group hypopituitarism (mostly due to empty sella, Sheehan's syndrome and pituitary tumors) had not been recognized previously, and in 12 cases recurrent hyponatremia during previous hospital admissions (up to four times) could be documented. The mean age of these patients ( 21 women, seven men) was 68 years. The most frequently occurring clinical signs were missing or scanty pubic and axillary hair, pale and doughy skin, and small testicles in the men. Frequent symptoms like nausea and vomiting, confusion, disorientation, somnolence or coma were similar to those in 91 patients with SIADH. Basal serum cortisol levels in the acutely ill state ranged from 20 to $439 \mathrm{nmol} / \mathrm{l}$ (mean \pm s.D.: $157 \pm 123$ ), while in 30 other severely hyponatremic patients it ranged from 274 to $1732 \mathrm{nmol} / \mathrm{l}(732 \pm 351 \mathrm{nmol} / \mathrm{l})$. In most patients with hyponatremic hypopituitarism, plasma antidiuretic hormone levels were inappropriately high, probably due to a failure of endogenous cortisol to suppress the hormone in a stressful situation. All patients recovered after low-dose hydrocortisone substitution. Most patients had other pituitary hormone deficiencies and were appropriately substituted subsequently.

Conclusions: Hypopituitarism including secondary adrenal insufficiency seems to be a frequently overlooked cause of severe hyponatremia. A high level of suspicion is the best way to recognize the underlying disorder. Treatment with hydrocortisone is very effective.
\end{abstract}

European Journal of Endocrinology 148 609-617

\section{Introduction}

Hyponatremia can have multiple causes. A worldwide accepted diagnostic scheme is that of Berl and Schrier (1) who differentiated the causes (a) hypovolemia or primary sodium deficiency from (b) arterial underfilling in edematous disorders like severe heart failure or hydropic liver cirrhosis and (c) normovolemic states with 'inappropriate vasopressin secretion'. 'Inappropriate' means not caused by plasma hyperosmolality or by arterial hypotension or hypovolemia. In their first extensive review on the 'syndrome of inappropriate secretion of antidiuretic hormone' (SIADH), Bartter and Schwartz (2) gave a definition of the syndrome, which, among others, excluded cases of hyponatremia caused by adrenal insufficiency and hypopituitarism. Severe hyponatremia can be a leading symptom of acute Addison's disease (primary adrenal insufficiency). In this syndrome, mineralocorticoid (aldosterone, deoxycorticosterone, cortisol) deficiency, sodium wasting and extracellular hypovolemia seem to be the main causes of hyponatremia. The most direct cause, however, is vasopressin hypersecretion with consecutive renal water retention, an 'appropriate' response to hypovolemia and hypotension. Severe hyponatremia can, however, also occur in patients with secondary 
adrenal insufficiency in the absence of hypovolemia and dehydration, and it is rapidly corrected by hydrocortisone substitution (3). In a previous paper from our group, we described five elderly women with this syndrome, in whom plasma vasopressin was elevated in spite of indirect signs of mild extracellular volume expansion (4). This condition is clinically similar to SIADH. Several other publications confirmed our results (5-9). The main cause of hyponatremia in this condition seems to be a failure of endogenous cortisol to exert a tonic inhibitory effect on vasopressin secretion $(10,11)$, although in some of these patients the cause of hyponatremia is multifactorial.

In the following paper, we describe clinical features of 28 patients with hypopituitarism and severe hyponatremia, who were seen between 1981 and 2000 in one endocrine unit. In 25 of these patients (89\%), hypopituitarism with secondary adrenal insufficiency was undiagnosed before the hyponatremic episode led to its discovery, and 12 patients $(43 \%)$ had hyponatremic episodes previously, the cause of which (hypopituitarism) remained undiagnosed.

\section{Subjects and methods}

We reviewed 185 files of patients of this hospital with the main entry diagnosis 'hyponatremia' (serum sodium concentration $<130 \mathrm{mmol} / \mathrm{l}$ ), who were either inpatients of the endocrine unit or in the diagnostic workup of whom endocrinologists of this division were involved. Most patients had been initially admitted to the intensive care unit, and some patients were referred to the endocrine unit from other city hospitals. Patients with acute primary adrenal insufficiency were excluded, because they had more severe leading symptoms different from hyponatremia. In 139 cases the data were sufficient to allow a classification according to the criteria of Berl and Schrier (1). However, in the remaining 46 patients, clinical signs of hypopituitarism were absent, and in several cases basal cortisol measurements or, in some cases, adrenal function tests were performed and found normal.

The main purpose of our search was to find patients with proven hypopituitarism and secondary adrenal insufficiency as the underlying cause of severe hyponatremia. This approach was different from that of Gross et al. (12) and Anderson et al. (13), who both prospectively studied the incidence and prevalence of hyponatremia in medical and surgical departments of university hospitals, and therefore saw a much higher percentage of diuretic-treated patients with congestive heart failure or liver cirrhosis, in the diagnostic workup of which we were rarely involved.

Diagnostic criteria of normovolemic hyponatremia and of SIADH were as follows: hyponatremia; plasma hypo-osmolality; urinary osmolality $>$ serum osmolality or urinary osmolality $>100 \mathrm{mosmol} / \mathrm{kg}$; initial urinary sodium concentration $>30 \mathrm{mmol} / \mathrm{l}$; absence of clinical signs of dehydration/hypovolemia, of increased creatinine or uric acid levels, of severe congestive heart failure or liver cirrhosis and of arterial hypotension.

Diagnostic criteria of secondary adrenal insufficiency were either a serum or plasma cortisol level below $100 \mathrm{nmol} / \mathrm{l}$ in the morning (confirmed by a second determination) without an elevated plasma adrenocorticotropin (ACTH) and/or renin level (14, 15), an insufficient response of cortisol to either insulininduced hypoglycemia, or to $100 \mu \mathrm{g}$ human corticotropin-releasing hormone $(\mathrm{CRH})$, or to $250 \mu \mathrm{g} \mathrm{ACTH}$ 1-24 (Synacthen), or an insufficient response at $0800 \mathrm{~h}$ of serum 11-deoxy-cortisol and plasma ACTH in the overnight metyrapone test. These tests and the lower normal cutoff limits of the adrenal function tests were described elsewhere (14), and they are also given in the legend to Table 3. The dynamic adrenal hormone tests and other endocrine tests were performed once the patients had recovered from acute illness, and after suspending hydrocortisone substitution for at least $24 \mathrm{~h}$. On the day of admission or as early as possible we attempted to measure basal plasma cortisol, ACTH, vasopressin, renin activity and aldosterone levels. Thereafter, oral or intravenous hydrocortisone treatment (between 25 and $50 \mathrm{mg}$ per day) was started, besides other therapeutic measures, if hypopituitarism was suspected to be an underlying disorder or if the initial cortisol level turned out to be relatively low. In some patients with hypopituitarism, plasma vasopressin was remeasured after the correction of hyponatremia (serum sodium $>135 \mathrm{mmol} / \mathrm{l}$ ).

Plasma or serum cortisol were measured by radioimmunoassay, using a Diagnostic Product Corporation's kit, distributed by H Biermann, Bad Nauheim, Germany. Plasma ACTH was measured in EDTAplasma by a double antibody immunoradiometric assay (Allegro HS-ACTH) purchased from Nichols Insitute (San Juan Capistrano, CA, USA). Before 1988, an ACTH RIA kit from Sorin Biomedica (Saluggia, Italy) was used. The normal range for both methods was similar ( 5 to $45 \mathrm{pg} / \mathrm{ml}$ ). Plasma vasopressin was measured using the method of Morton et al. (16) employing an antiserum kindly provided by JJ Morton (Glasgow, UK). The detection limit for vasopressin in extracted plasma was $0.1-0.2 \mathrm{pmol} / \mathrm{l}$, and the normal range in normally hydrated healthy subjects was $0.3-0.9 \mathrm{pmol} / \mathrm{l}$. Plasma renin activity and plasma or urinary aldosterone were measured as described previously (15). Plasma and urinary osmolality were measured with an osmometer from Roebling, Berlin, Germany. Serum and urinary electrolyte concentrations, other routine parameters, thyroid, gonadal and other pituitary hormones were measured in the central laboratory of this hospital with standardized methods under regular quality control by the German Society of Clinical Chemistry. 


\section{Results}

Of the 139 patients evaluated, 28 had hypopituitarism and secondary adrenal insufficiency. Twenty-one of them $(75 \%)$ were women. The age of the women ranged between 49 and 89 years (mean 68 years), that of the seven men between 47 and 79 years (mean: 67 years). Ninety-one patients had SIADH. In 51 of these cases the cause could be determined (bronchogenic carcinoma, 22; other tumors, six; acute pulmonary disease, 10; head injury, meningitis or subarachnoidal hemorrhage, 12; severe gastric nausea, one). In 40 cases the cause of SIADH seemed to be multifactorial or unclear. The average age of patients with SIADH was about 10 years younger than those with hyponatremic hypopituitarism. Nineteen patients with severe hyponatremia had hypervolemic or hypovolemic disorders (heart failure, six; liver cirrhosis, six; diuretic overdose, seven). One patient had renal insufficiency and, in addition, a suprasellar tumor.

Because our searching procedure was retrospective and selective for patients documented by one hospital unit, we do not regard the 28 cases of hyponatremic hypopituitarism as the true incidence of hospital admissions with this disorder over the last 20 years.

\section{Characterization of patients with hypopituitarism and hyponatremia}

Serum sodium concentration at admission ranged between 105 and $127 \mathrm{mmol} / \mathrm{l}$ (mean \pm s.D., $116 \pm 7 \mathrm{mmol} / \mathrm{l}$ ) (Table 1). Mean plasma osmolality was $256 \pm 16 \mathrm{mosmol} / \mathrm{kg}$, urinary osmolality $(n=14)$ was $399 \pm 108 \mathrm{mosmol} / \mathrm{kg}$, and urinary sodium concentration $(n=11)$ was $110 \pm 49 \mathrm{mmol} / \mathrm{l}$ (Table 1$)$. None of the patients was hyperkalemic. Plasma vasopressin was measured before hydrocortisone therapy in 20 patients. The mean level was $4.58 \pm 7.7 \mathrm{pmol} / \mathrm{l}$. The large variability was due to two patients with vasopressin levels $>25 \mathrm{pmol} / \mathrm{l}$, and to five patients in whom vasopressin was not detectable at the time of measurement (Fig. 1). Plasma renin activity ranged between 0.2 and $3.8 \mathrm{ng} / \mathrm{ml} / \mathrm{h}$ (mean: $1.58 \pm 1.2 \mathrm{ng} / \mathrm{ml} / \mathrm{h}$ ). The normal range in recumbent subjects is $1-4.5 \mathrm{ng} / \mathrm{ml} / \mathrm{h}$. Plasma or urinary aldosterone (Table 1) was also low or normal in all patients in whom it was measured $(n=18)$ shortly after admission. Serum creatinine was below the normal range in three patients, normal in 23, and slightly elevated (129 and $188 \mathrm{nmol} / \mathrm{l})$ in two elderly diabetics, in whom the raised levels were known before admission. Uric acid was below the normal range in four patients, normal in 21 , and slightly increased in the two diabetics and in another man.

The most frequently observed clinical signs in these patients were absent or scanty axillary and pubic hair (86\%), followed by a pale, doughy skin in $71 \%$. Five of the seven men in this group had small $(<12 \mathrm{ml})$ and soft testicles (Table 2). On admission, 75\% of the patients complained of nausea or had vomited, $32 \%$ were disoriented or confused, while $36 \%$ were precomatous or comatous. A number of patients complained of abdominal pain, headaches, diarrhea or vertigo.

In five patients, the rectal temperature was $38^{\circ} \mathrm{C}$ or higher. Eight patients had bronchial or pulmonary infections, two had influenza-like infections, one had a herpes simplex-encephalitis, and one a staphylococcal bacteremia. One woman was hypoglycemic. These conditions, as unspecific stressors, and nausea and vomiting may have been triggers of vasopressin secretion in the patients with hypopituitarism. In patients 3 and 12, the use of furosemide tablets before admission (because of mild congestive heart failure and mild diabetic nephropathy respectively) may have aggravated the hyponatremia.

When the patients had recovered from acute illness, $54 \%$ reported that they had suffered weakness and tiredness during the preceding years, 32\% had had unexplained weight loss, two patients each reported chronic depression and visual disturbances and all men had suffered reduced libido and sexual potency. Nine women, aged between 49 and 89 years, reported an early menopause (42 years or younger), in five cases immediately or a few years after a delivery with severe blood loss and/or very low blood pressure.

Of note, in only three patients (numbers 3, 16 and 20) had hypopituitarism been diagnosed before the present admission. Two of these patients were untreated, and one did not take her hydrocortisone tablets regularly. Twelve patients had previously been admitted between one and four times to other hospitals because of severe hyponatremia, but the underlying disorder (hypopituitarism) was not recognized.

\section{Pituitary and adrenal function tests and radiological studies of the pituitary region}

Basal plasma cortisol shortly after admission was below $100 \mathrm{nmol} / \mathrm{l}$ in 13 patients, below $200 \mathrm{nmol} / \mathrm{l}$ in 21 patients and 'normal' (for unstressed subjects) in seven cases (Table 3). The highest basal plasma cortisol level was $439 \mathrm{nmol} / \mathrm{l}$. The mean cortisol level was $157 \pm 123 \mathrm{nmol} / \mathrm{l}$. The initial basal cortisol level did not correlate significantly with serum sodium $(r=-0.29 ; P>0.05)$. In 20 patients in whom basal plasma ACTH was measured, it ranged between $<5$ and $41 \mathrm{pg} / \mathrm{ml}$ (mean level: $17.2 \pm 10.5 \mathrm{pg} / \mathrm{ml}$ ). One or more dynamic adrenal function tests were pathological in all cases (Table 3). Hypoglycemia-stimulated growth hormone was $<5 \mu \mathrm{g} / \mathrm{l}$ in 13 patients in whom the test was performed. Gonadotropins were below normal in six out of seven men, and serum testosterone was $<9 \mathrm{nmol} / \mathrm{l}$ in the same subjects. In all women, gonadotropins were either below normal or too low for the postmenopausal state. Thyrotropin (TSH) and thyroid hormones were lowered in 15 and normal in eight 
Table 1 Electrolytes, creatinine and renin/aldosterone levels in 28 patients (21 females, seven males) with hyponatremic hypopituitarism.

\begin{tabular}{|c|c|c|c|c|c|c|c|c|c|c|}
\hline Patient & Age & Gender & Year of diagnosis & $\begin{array}{c}\text { S-Sodium } \\
(\mathrm{nmol} / \mathrm{l})\end{array}$ & $\begin{array}{c}\text { P-Osm } \\
(\mathrm{mosmol} / \mathrm{kg})\end{array}$ & $\underset{(\mu \mathrm{mol} / \mathrm{l})}{\text { S-Creatinine }}$ & $\begin{array}{l}\text { P-AVP } \\
\text { (pmol/l) }\end{array}$ & $\begin{array}{c}\text { PRA } \\
(\mathrm{ng} / \mathrm{ml} / \mathrm{h})\end{array}$ & $\begin{array}{l}\text { P-Aldo } \\
\text { (nmol//) }\end{array}$ & $\begin{array}{c}\text { U-Aldo } \\
\text { (nmol/24h) }\end{array}$ \\
\hline $1 \mathrm{MB}$ & 84 & $f$ & 1990 & 108 & 246 & 87 & $<0.18$ & & & 25.6 \\
\hline $2 \mathrm{SB}$ & 69 & $f$ & 1999 & 113 & 274 & 57 & & 3.5 & 0.22 & \\
\hline $3 \mathrm{GJ}$ & 71 & $f$ & 1991 & 116 & 269 & 101 & & 0.6 & 0.14 & \\
\hline $4 \mathrm{IL}$ & 67 & $f$ & 2000 & 110 & 216 & 62 & & & & \\
\hline $5 \mathrm{IM}$ & 60 & $f$ & 1988 & 127 & 264 & 129 & 4.06 & 2.1 & 0.13 & 7.8 \\
\hline $6 \mathrm{MM}$ & 59 & $f$ & 1985 & 126 & 236 & 80 & 1.30 & 0.8 & & \\
\hline 7 EN & 70 & $f$ & 1989 & 126 & 260 & 79 & $<0.18$ & & & \\
\hline $8 \mathrm{BO}$ & 61 & $f$ & 1988 & 121 & 252 & 78 & 1.58 & 3.4 & 0.4 & \\
\hline 9 BP & 49 & $f$ & 1999 & 113 & 265 & 73 & 0.18 & & & \\
\hline $10 \mathrm{ER}$ & 61 & $\mathrm{~m}$ & 2000 & 108 & & 88 & & & & \\
\hline $11 \mathrm{KS}$ & 66 & $\mathrm{~m}$ & 1997 & 127 & 271 & 65 & 2.08 & 0.9 & $<0.07$ & \\
\hline $12 \mathrm{WW}$ & 82 & $f$ & 1997 & 118 & 262 & 188 & & 3.1 & 0.16 & \\
\hline $13 \mathrm{IB}$ & 57 & $f$ & 1993 & 104 & 264 & 56 & 1.08 & 1.2 & 0.5 & \\
\hline 14 UG & 60 & $f$ & 1992 & 108 & 265 & 67 & 1.25 & 0.3 & 0.12 & 13.4 \\
\hline $15 \mathrm{WJ}$ & 72 & $f$ & 1984 & 120 & & 62 & & & & \\
\hline 16 LK & 47 & $\mathrm{~m}$ & 1992 & 120 & 275 & 70 & $>22$ & 1.8 & 0.71 & \\
\hline $17 \mathrm{GP}$ & 72 & $f$ & 1987 & 111 & 250 & 44 & $>25$ & 1 & 0.69 & \\
\hline 18 WP & 78 & $\mathrm{~m}$ & 1991 & 124 & & 72 & & & & \\
\hline $19 \mathrm{HU}$ & 79 & $\mathrm{~m}$ & 1995 & 112 & 263 & 78 & $<0.18$ & 2.7 & 0.19 & 1.6 \\
\hline $20 \mathrm{ES}$ & 65 & $f$ & 1992 & 120 & 254 & 45 & $<0.18$ & 0.2 & 0.07 & \\
\hline $21 \mathrm{CK}$ & 59 & $f$ & 1998 & 105 & 224 & 86 & 0.46 & & & \\
\hline $22 \mathrm{MS}$ & 72 & $f$ & 1981 & 124 & 260 & 60 & 5.90 & 0.6 & & 8.9 \\
\hline $23 \mathrm{FB}$ & 69 & $f$ & 1997 & 105 & 230 & 39 & 0.75 & 3.8 & 0.38 & \\
\hline $24 \mathrm{~GB}$ & 83 & $f$ & 1988 & 121 & 244 & 59 & 10.70 & 0.6 & 0.16 & \\
\hline $25 \mathrm{~EB}$ & 68 & $f$ & 1991 & 120 & 264 & 88 & 0.53 & 0.3 & 0.32 & 17.9 \\
\hline $26 \mathrm{AL}$ & 89 & $f$ & 1989 & 125 & 266 & 54 & $<0.18$ & & & \\
\hline $27 \mathrm{HR}$ & 74 & $\mathrm{~m}$ & 2000 & 130 & 278 & 92 & 5.81 & & 0.14 & \\
\hline $28 \mathrm{HP}$ & 63 & $\mathrm{~m}$ & 1999 & 111 & & 106 & & & & \\
\hline Mean & 68 & & & 116.89 & 256.33 & 77.32 & 4.58 & 1.58 & 0.29 & 12.53 \\
\hline SD & 10 & & & 7.65 & 15.98 & 28.92 & 7.71 & 1.22 & 0.20 & 7.70 \\
\hline Normal range & & & & $135-149$ & $277-300$ & $50-110$ & $0.3-0.9$ & $1.0-4.5$ & $0.15-0.5$ & $3.7-5.3$ \\
\hline
\end{tabular}

$\mathrm{S}$, serum; P, plasma; U, urinary; Osm, osmolality; AVP, arginine vasopressin; PRA, plasma renin activity; Aldo, aldosterone. 


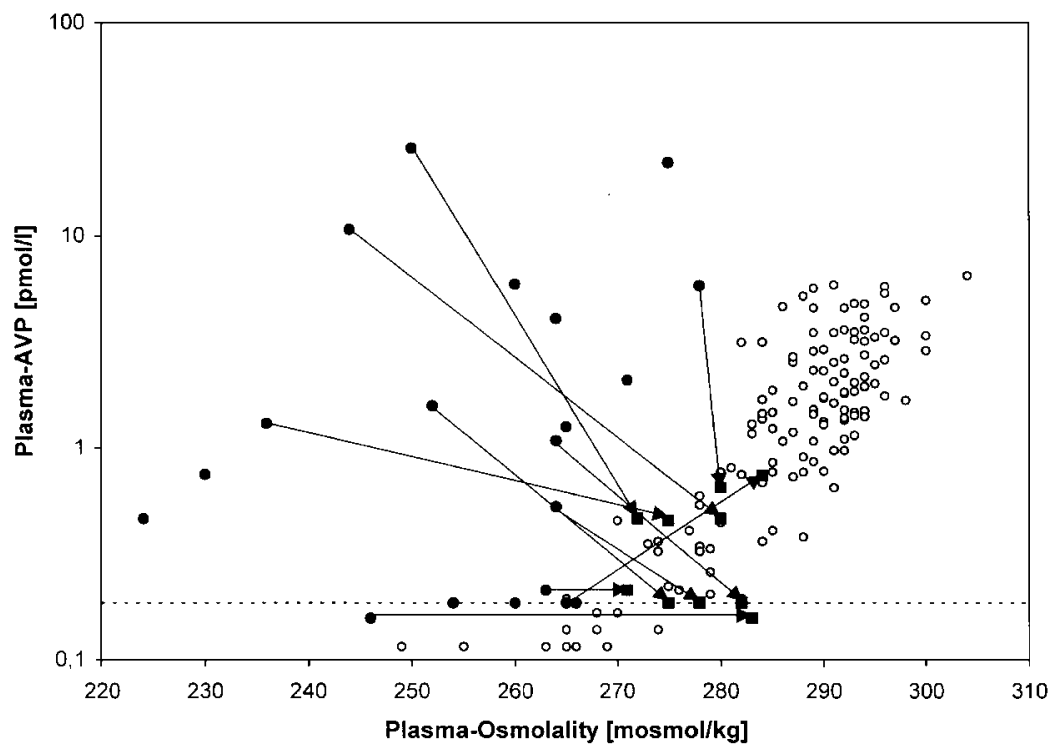

Figure 1 Relationship between plasma osmolality and plasma vasopressin (AVP) in 20 patients with hyponatremia and hypopituitarism (solid circles) in comparison with hydrated and dehydrated levels in normal subjects (open circles). In 10 patients, the levels were remeasured after normalization of serum sodium following hydrocortisone treatment (solid squares). patients, while test results were unclear or not available in the remaining five patients. Basal and/or hypoglycemia-stimulated prolactin was lowered in 19, and normal in four patients. In three patients, basal prolactin was slightly increased, probably due to a functional disruption of the pituitary stalk.

Except in patient no. 20, who had a pituitary tumor operated on at the age of 20 years, magnetic resonance imaging (MRI) $(n=16)$ and/or cranial computed tomography (CT) scans $(n=23)$ were performed in all patients. Twelve patients, among them two males, had an 'empty sella'. In six of the women with an empty sella and in another one with normal radiological findings, the history was in favor of the diagnosis of Sheehan's syndrome or, alternatively, a state after lymphocytic hypophysitis.

Six patients had pituitary tumors, two had sellar meningeomas and one patient probably had an old infarction of a pituitary tumor. In six cases the MRI or cranial CT scans were normal. One of the 28 patients

Table 2 Symptoms and signs in 28 patients with hyponatremic hypopituitarism.

\begin{tabular}{lcc}
\hline Symptoms & Incidence & Percent \\
\hline Missing/scanty axillary/pubic hair & $24 / 28$ & 85.7 \\
Nausea/vomiting & $21 / 28$ & 75.0 \\
Testicular volume $<12 \mathrm{ml}$ & $5 / 7$ & 71.4 \\
Pale, doughy skin & $20 / 28$ & 71.4 \\
Somnolence/coma & $10 / 28$ & 35.7 \\
Confusion/disorientation & $9 / 28$ & 32.1 \\
Abdominal pain & $8 / 28$ & 28.6 \\
Headache & $5 / 28$ & 17.9 \\
Seizures & $5 / 28$ & 17.9 \\
Diarrhea & $5 / 28$ & 17.9 \\
Vertigo & $4 / 28$ & 14.3 \\
\hline
\end{tabular}

had secondary adrenal insufficiency due to chronic treatment with pharmacological doses of prednisolone because of ankylosing spondylitis.

\section{Treatment of hyponatremia and adrenal insufficiency}

All patients were initially treated with water restriction. Most patients received varying amounts of normal saline intravenously, and some patients were cautiously treated with infusions of $3 \% \mathrm{NaCl}$. All patients were given oral or intravenous hydrocortisone $(20-50 \mathrm{mg}$ a day), beginning between days 1 and 5 after admission, which usually led to a return of serum sodium into the normal range within 3-5 days. The decision for hydrocortisone treatment was taken either when clinical suspicion of adrenal insufficiency arose (see Table 2) or when in these severely ill patients serum cortisol was suspiciously low. Since this was not a prospective study, no sharp lower cutoff point for cortisol can be given. Some patients with hyponatremia, who later turned out not to have hypopituitarism, inevitably were also treated with hydrocortisone. We never observed an extremely rapid water diuresis after hydrocortisone administration that made free water infusion ( $5 \%$ glucose) or the administration of desmopressin necessary. There were no fatalities or clinical indications of a cerebral demyelinization disorder as the consequence of too rapid normalization of serum sodium. Figure 1 shows the results of plasma arginine vasopressin (AVP) measurements in relation to plasma osmolality in comparison with the normal range, which was obtained by taking blood from 15 normal subjects in the state of dehydration and normal hydration. In seven patients with hyponatremia and hypopituitarism in whom AVP was measured 
Table 3 Adrenal and pituitary hormones, and causes of hypopituitarism in 28 patients with hyponatremia. Basal serum(s) cortisol levels in acutely ill patients. Other tests after recovery.

\begin{tabular}{|c|c|c|c|c|c|c|c|c|c|c|c|c|}
\hline \multirow[b]{2}{*}{ Patient } & \multirow[b]{2}{*}{ Age } & \multirow[b]{2}{*}{ Gender } & \multirow[b]{2}{*}{$\begin{array}{c}\text { S-Cortisol } \\
(\mathrm{nmol} / \mathrm{l})\end{array}$} & \multicolumn{4}{|c|}{$\begin{array}{c}\text { Adrenal tests } \\
\text { (responses, nmol/l) }\end{array}$} & \multicolumn{4}{|c|}{ Other pituitary axes } & \multirow[b]{2}{*}{ MRI or cranial CT diagnosis } \\
\hline & & & & $\begin{array}{l}\text { Synacthen } \\
\text { test }\end{array}$ & $\begin{array}{l}\text { Metyrapone } \\
\text { test }\end{array}$ & $\mathrm{CRH}$ test & $\begin{array}{l}\text { Insulin } \\
\text { test }\end{array}$ & $\begin{array}{l}\text { GH after } \\
\text { insulin }\end{array}$ & $\begin{array}{c}\mathrm{FSH} \\
\mathrm{LH}\end{array}$ & $\begin{array}{l}\mathrm{TSH} \\
\mathrm{T}_{3}, \mathrm{~T}_{4}\end{array}$ & Prolactin & \\
\hline $1 \mathrm{MB}$ & 84 & $\mathrm{f}$ & 368 & & & & 438 & - & - & n.a. & - & Empty sella, suspected Sheehan's \\
\hline $2 \mathrm{SB}$ & 69 & $f$ & 196 & & 45 & 361 & & n.a. & - & - & - & Empty sella \\
\hline $3 \mathrm{GJ}$ & 71 & $f$ & 193 & 454 & & & & n.a. & - & - & - & Empty sella, suspected Sheehan's \\
\hline $4 \mathrm{IL}$ & 67 & f & 63 & & & & 140 & - & - & - & - & Empty sella, suspected Sheehan's \\
\hline $5 \mathrm{IM}$ & 60 & f & 105 & 473 & & 139 & & n.a. & - & - & - & Empty sella, suspected Sheehan's \\
\hline $6 \mathrm{MM}$ & 59 & f & 25 & & 5 & 240 & 110 & - & - & - & - & Empty sella, suspected Sheehan's \\
\hline $7 \mathrm{EN}$ & 70 & f & 30 & 191 & & & & n.a. & - & - & - & Empty sella \\
\hline $8 \mathrm{BO}$ & 61 & f & 340 & & 85 & 305 & & n.a. & - & - & - & Empty sella \\
\hline $9 \mathrm{BP}$ & 49 & $\mathrm{f}$ & 385 & & 115 & & 406 & - & - & + & + & Empty sella, suspected Sheehan's \\
\hline $10 \mathrm{ER}$ & 61 & $\mathrm{~m}$ & 103 & & & 112 & & n.a. & - & - & - & Empty sella \\
\hline $11 \mathrm{KS}$ & 66 & $\mathrm{~m}$ & 217 & & 23 & & & n.a. & - & + & - & Empty sella \\
\hline $12 \mathrm{WW}$ & 82 & $f$ & 64 & 424 & & 231 & 265 & - & - & - & - & Empty sella \\
\hline $13 \mathrm{IB}$ & 57 & f & 439 & & 16 & 361 & & n.a. & - & n.a. & - & Sellar meningeoma \\
\hline $14 U G$ & 60 & f & 181 & 243 & & & & n.a. & - & - & ++ & Sellar meningeoma \\
\hline $15 \mathrm{WJ}$ & 72 & $f$ & 88 & 469 & 75 & & 223 & - & - & + & - & Intra/supra-sellar tumor \\
\hline $16 \mathrm{LK}$ & 47 & $\mathrm{~m}$ & 82 & & & & 86 & - & - & n.a. & ++ & Macroprolactinoma \\
\hline $17 \mathrm{GP}$ & 72 & $f$ & 67 & 174 & & & 70 & - & - & n.a. & - & Intra/para-sellar tumor \\
\hline 18 WP & 78 & $\mathrm{~m}$ & 84 & & & 325 & 120 & - & - & + & n.a. & Intrasellar tumor \\
\hline $19 \mathrm{HU}$ & 79 & $\mathrm{~m}$ & 308 & & 23 & 399 & & n.a. & - & - & + & Intrasellar tumor \\
\hline $20 \mathrm{ES}$ & 65 & $f$ & 110 & & & & 145 & - & - & n.a. & - & Postop. (1952) partial empty sella \\
\hline $21 \mathrm{CK}$ & 59 & f & 35 & & 19 & & & n.a & - & - & ++ & Infarcted intrasellar tumor \\
\hline $22 \mathrm{MS}$ & 72 & f & 50 & 437 & & & 147 & - & - & + & - & Normal, suspected Sheehan's \\
\hline $23 \mathrm{FB}$ & 69 & f & 163 & & 176 & & & n.a. & - & - & n.a. & Normal \\
\hline $24 \mathrm{~GB}$ & 83 & f & 87 & & 93 & 166 & & n.a. & - & + & + & Normal \\
\hline $25 \mathrm{~EB}$ & 68 & f & 132 & & & 207 & 274 & - & - & + & - & Normal \\
\hline $26 \mathrm{AL}$ & 89 & f & 355 & & & & 457 & - & - & - & - & Normal \\
\hline $27 \mathrm{HR}$ & 74 & $\mathrm{~m}$ & 57 & 436 & 92 & 315 & & n.a. & + & + & + & Normal \\
\hline $28 \mathrm{HP}$ & 63 & $\mathrm{~m}$ & 70 & & & 50 & & n.a. & - & - & - & Postglucocorticoid syndrome \\
\hline
\end{tabular}

Adrenal tests with lower normal response limits: Synacthen - $60 \mathrm{~min}$ cortisol, $550 \mathrm{nmol} / /$; Metyrapone - 11-deoxy-cortisol at $0800 \mathrm{~h}, 200 \mathrm{nmol} / \mathrm{h}$; CRH test - peak cortisol, $450 \mathrm{nmol} / \mathrm{l}$; insulin test - peak cortisol, $550 \mathrm{nmol} / \mathrm{l}$.

Evaluation of pilutary tests. -, decreased level/response; + , normal level/response; ++ , increased level, n.a., not available.

$\mathrm{GH}$, growth hormone; FSH, follicle-stimulating hormone; LH, luteinizing hormone (gonadotropins); $\mathrm{T}_{4}$, thyroxine; $\mathrm{T}_{3}$, tri-iodothyronine. 
before and after correction of the hyponatremia, an inappropriately raised AVP level returned into the normal range. In two patients with low initial AVP levels, the value remained unchanged, while in one case a level of $0.2 \mathrm{pmol} / \mathrm{l}$ rose to $1 \mathrm{pmol} / \mathrm{l}$ after correction of hyponatremia.

\section{Discussion}

Hyponatremia is one of the most frequently occurring electrolyte disturbances in hospitals. Mild cases are often asymptomatic, but severe hyponatremia may cause dramatic symptoms and a high mortality (13) depending on the speed of its development and the underlying disorder. The relatively great percentage of severely hyponatremic patients with hypopituitarism and secondary adrenal insufficiency reported here is partly explained by referral bias and by neglection of patients with edematous disorders (heart failure, liver cirrhosis), as stated previously. However, 28 patients diagnosed with this disorder in 20 years means that the condition is rare but not very rare. Bethune and Nelson (3) reported on a series of eight patients with hyponatremia and mixed pituitary disorders, Kimura et al. (6) on eight patients, mostly with isolated corticotropin deficiency, Kamoi et al. (7) on seven patients with ACTH or CRH deficiency, Yamamoto et al. (8) on 11 patients, and Ishikawa et al. (9) on 13 patients with the hyponatremic-hypocortisolemic disorder, which were probably diagnosed in the course of a few years. On average, hyponatremia was less severe in the reports cited above than in our patients, and the clinical picture was less extensively characterized than in the present paper. Yamamoto et al. (8) made the interesting observation that a subgroup of their patients with hyponatremic hypopituitarism were slightly dehydrated "with regard to body weight, blood pressure, total proteins, hematocrit and blood urea nitrogen', but they responded poorly to intravenous fluid supplementation, similar to the patients with clearcut dilutional hyponatremia and hypocortisolism, while in both subgroups hyponatremia was corrected by hydrocortisone administration. We are not aware of such a dehydrated subgroup in our 28 patients with hyponatremic hypopituitarism, whose renin and aldosterone levels were normal or suppressed, but it has to be admitted that mild dehydration is difficult to diagnose in elderly patients.

A point of practical relevance for clinicians is the fact that in all except three patients of our series chronic hypopituitarism was unknown before it was diagnosed at the occasion of hospital admission because of symptomatic hyponatremia. Another important point is the recurrent nature of hyponatremia in 12 of 28 patients. Hypopituitarism had obviously not been considered as a cause of hyponatremia when the patients had been admitted previously. Therefore, hypopituitarism should be thought of in all patients with an SIADH-like clinical constellation without an obvious cause (e.g. bronchogenic carcinoma), and perhaps even in patients who appear to be mildly dehydrated (8). A careful physical examination is helpful (Table 2), while taking the history with regard to suspicious symptoms of hypopituitarism may have to be delayed in patients with mental disturbances in the state of hyponatremia.

A basal serum or plasma cortisol level should be obtained as early as possible. A short Synacthen test on the day of admission may also be helpful. In the case of clinical suspicion of hypopituitarism or once the cortisol level is available and is suspiciously low in these severely ill patients, hydrocortisone therapy should be instituted, while the clinical condition and the serum sodium level are closely monitored. If hydrocortisone administration should lead to massive excretion of a dilute urine and a rapid increase in serum sodium concentration, its rise can be delayed by the infusion of 'free water' (e.g. 5\% glucose solution) or by the administration of desmopressin.

Many studies support the concept that hyponatremia in patients with hypopituitarism is mainly caused by failing inhibition of vasopressin secretion because of hypocortisolism. Cortisol is a physiological tonic inhibitor of vasopressin secretion $(10,11)$. Inadequate thirst in spite of developing hypo-osmolality, and the stimulation of AVP secretion by stressors (infections, hypoglycemia, nausea and vomiting) may aggravate the hyponatremic condition $(17,18)$. Later on, urinary sodium loss may supervene following extracellular volume expansion, suppression of renin and aldosterone and, perhaps, an increase of atrial natriuretic hormone (6). In five of our patients, plasma AVP was undetectable at the time of measurement. This could mean that a previous, transient increase of plasma AVP was missed or that mechanisms other than an elevated AVP level had caused the hyponatremia. In the majority of patients, elevated AVP levels in the hypo-osmolar state and a fall of AVP following hydrocortisone treatment in seven cases support the concept of failing inhibition of AVP secretion by cortisol in this syndrome.

Most patients of the present study had secondary hypothyroidism in addition to hypocortisolism. Severe hypothyroidism, mostly the primary form, can also be associated with an SIADH-like syndrome (19), but in our cases the response of hyponatremia to hydrocortisone administration was such a regular observation that the role of thyroid hormone deficiency in the genesis of the syndrome was probably small. All patients with hypothyroidism were of course substituted with thyroid hormone and other deficient hormones once the diagnosis of hypopituitarism had been made.

Secondary adrenal insufficiency differs biochemically from the primary form by the absence of hyperkalemia, of hyperreninemia and by low or normal ACTH levels. The diagnosis of severe secondary adrenal insufficiency 
is easy, but mild forms may be difficult to discover, because even with the application of 'gold standard' tests like the insulin hypoglycemia test or the metyrapone test, no sharp dividing line between normality and disease can be drawn $(20,21)$. The Synacthen test is less sensitive than the insulin or metyrapone test, but if cortisol is less than normally stimulated, the test is diagnostic of adrenal insufficiency if properly performed (22). Regarding the basal cortisol level, one has to consider that most patients with severe hyponatremia are candidates for an intensive care unit and that, in severely ill patients, the normal range of plasma cortisol of unstressed healthy subjects (approx. $200-600 \mathrm{nmol} / \mathrm{l}$ in the early morning hours) is a yardstick of limited value $(14,23)$. Many of our patients with hyponatremic hypopituitarism had subnormal basal cortisol levels in the acutely ill state. The patient with the highest level, but a pathological metyrapone and $\mathrm{CRH}$ test after recovery, had a cortisol level of $439 \mathrm{nmol} / \mathrm{l}$ in the state of acute illness (patient 13). Thus the range of basal cortisol levels in these patients was between 25 and $439 \mathrm{nmol} / \mathrm{l}$. In 30 patients with severe hyponatremia without hypopituitarism, in whom serum cortisol was measured in the acute condition, it ranged betweeen 274 and $1732 \mathrm{nmol} / \mathrm{l}$ (mean: $732 \pm 351 \mathrm{nmol} / \mathrm{l})$. Therefore, hypopituitarism in severely hyponatremic patients should be considered to be present if suspicious clinical signs or symptoms are found or if the cortisol level is $<440 \mathrm{nmol} / \mathrm{l}$, although a considerable proportion of patients with levels below $440 \mathrm{nmol} / \mathrm{l}$ will probably have normal dynamic adrenal function tests once they are being tested after recovery from hyponatremia. However, the application of low doses of hydrocortisone in a hyponatremic patient without hypopituitarism will rarely be harmful, while the failure to give hydrocortisone to a patient with the disorder can have serious, in some cases, lethal consequences. Thus the decision whether to give or not to give hydrocortisone is discretionary in some cases. The best means to detect the patient with hypopituitarism among others with severe hyponatremia is a high level of clinical suspicion.

\section{Acknowledgements}

The authors are grateful to Professor Theodor Dissmann, and Privat-Dozent Jürgen-Heiner Schäfer for excellent cooperation with the Endocrine Unit while they were in charge of the admission ward and the Intensive Care Unit of Klinikum Benjamin Franklin (Freie Universität Berlin).

\section{References}

1 Berl T \& Schrier RW. Disorders of water metabolism. In Renal and Electrolyte Disorders, 5th edn, pp 1-71. Ed. RW Schrier. Philadelphia: Lippincott-Raven Press, 1997.
2 Bartter FC \& Schwartz WB. The syndrome of inappropriate secretion of antidiuretic hormone. American Journal of Medicine $196742790-806$.

3 Bethune JE \& Nelson DH. Hyponatremia in hypopituitarism. New England Journal of Medicine 1965272 771-776.

4 Oelkers W. Hyponatremia and inappropriate secretion of vasopressin (antidiuretic hormone) in patients with hypopituitarism. New England Journal of Medicine $1989321492-496$.

5 Oelkers W \& Hensen JJ. Syndrome of inappropriate antidiuretic hormone secretion (SIADH) in patients with hypopituitarism. In Vasopressin, pp 431-440. Eds P Gross, D Richter \& GL Robertson. Paris: John Libbey Eurotext, 1993.

6 Kimura T, Ota K, Shoji M, Inoue M, Sato K, Ohta M et al. Plasma vasopressin and atrial natriuretic hormone levels in hypopituitarism with and without hydrocortisone treatments; responses to an acute water load. Acta Endocrinologica 1992 $126217-223$.

7 Kamoi K, Tamiro T, Tanaka K, Ishibashi M \& Yamaji T. Hyponatremia and osmoregulation of thirst and vasopressin secretion in patients with adrenal insufficiency. Journal of Clinical Endocrinology and Metabolism 199377 1584-1588.

8 Yamamoto T, Fukuyama J, Kabayama Y \& Harada H. Dual facets of hyponatremia and arginine vasopressin in patients with ACTH deficiency. Clinical Endocrinology 199849 785-792.

9 Ishikawa S, Saito T, Fukagawa A, Higashiyama M, Nakamura T, Kusaka I et al. Close association of urinary excretion of aquaporin-2 with appropriate and inappropriate arginin vasopressin-dependent antidiuresis in hyponatremia in elderly subjects. Journal of Clinical Endocrinology and Metabolism 2001 $861665-1671$.

10 Raff H. Glucocorticoid inhibition of neurohypophysial vasopressin secretion. American Journal of Physiology $1987 \mathbf{2 5 2}$ R635-R644.

11 Erkut ZA, Pool C \& Swaab DF. Glucocorticoids suppress corticotropin-releasing hormone and vasopressin expression in human hypothalamic neurons. Journal of Clinical Endocrinology and Metabolism $1998 \mathbf{8 3} 2066-2073$.

12 Gross PA, Pehrisch H, Rascher W, Schömig A, Hackenthal E \& Ritz E. Pathogenesis of clinical hyponatremia: observations of vasopressin and fluid intake in 100 hyponatremic patients. European Journal of Clinical Investigation 1987 17 123-129.

13 Anderson RJ, Chung HM, Kluge R \& Schrier RW. Hyponatremia: a prospective analysis of its epidemiology and the pathogenetic role of vasopressin. Annals of Internal Medicine 1985102 164-168.

14 Oelkers W. Adrenal insufficiency. New England Journal of Medicine $19963351206-1212$.

15 Oelkers W, Diederich S \& Bähr V. Diagnosis and therapy surveillance in Addison's disease: rapid ACTH test and measurement of plasma ACTH, renin activity and aldosterone. Journal of Clinical Endocrinology and Metabolism $1992 \mathbf{7 5}$ 259-264.

16 Morton JJ, Connell JM, Hughes MJ, Inglis GC \& Wallace EC. The role of plasma osmolality, angiotensin II and dopamine in vasopressin release in man. Clinical Endocrinology $1985 \mathbf{2 3}$ 129-138.

17 Kovacs L \& Robertson GL. Syndrome of inappropriate antidiuresis. Endocrine and Metabolism Clinics of North America 199221 859-875.

18 Smith DM, McKenna K \& Thompson C. Hyponatremia. Clinical Endocrinology $2000 \mathbf{5 2} 667-678$.

19 Yonemura K, Furuya R, Oki Y, Matsushima H, Ohishi K \& Hishida A. Impaired water excretion in a hyponatremic patient following thyroidectomy: causal role of glucocorticoid deficiency. Mineral and Electrolyte Metabolism 199824 341-347.

20 Steiner H, Bähr V, Exner P \& Oelkers W. Pituitary function tests: comparison of ACTH and 11-deoxy-cortisol responses in the metyrapone test, and with the insulin hypoglycemia test. Experimental and Clinical Endocrinology and Diabetes 1994102 $33-38$. 
21 Tuchelt H, Dekker K, Bähr V \& Oelkers W. Dose-response relationship between plasma ACTH and serum cortisol in the insulin-hypoglycemia test in 25 healthy subjects and 109 patients with pituitary disease. Clinical Endocrinology 200053 301-307.

22 Mayenknecht J, Diederich S, Bähr V, Plöckinger U \& Oelkers W. Comparison of low and high dose corticotropin stimulation tests in patients with pituitary disease. Journal of Clinical Endocrinology and Metabolism $1998 \mathbf{8 3} 1558-1562$.
23 Lamberts SWJ, Bruining HA \& de Jong FH. Corticoid therapy in severe illness. New England Journal of Medicine 1997337 1285-1292.

Received 20 January 2003

Accepted 25 March 2003 